\title{
Does inhibitory dysfunction contribute to poor emotional aspect of eating behaviours in obesity? A study among a sample of young adults in Colombo District, Sri Lanka.
}

\author{
Nimantha Karunathilaka ${ }^{1}$, Chandana Hewage ${ }^{2}$, Savithri Wimalasekera ${ }^{2}$, Thamara Amarasekara ${ }^{3}$ \\ ${ }^{1}$ Department of Nursing \& Midwifery, Faculty of Allied Health Sciences, General Sir John Kotelawala Defence \\ University, Sri Lanka. \\ ${ }^{2}$ Department of Physiology, Faculty of Medical Sciences, University of Sri Jayewardenepura, Sri Lanka. \\ ${ }^{3}$ Department of Allied Health Sciences, Faculty of Medical Sciences, University of Sri Jayewardenepura, Sri Lanka.
}

\section{Article Information \\ Total number of \\ Words 3603 \\ Tables 03 \\ Authors have no conflicts of interest to declare}

Keywords: Inhibitory control, Emotional aspect of eating behaviour, Obesity and Young adults

Date of submission: 17.12.2107

Date of acceptance: 18.06.2018

Author responsible for correspondence: R.D. Nimantha Karunathilaka Department of Nursing \& Midwifery Faculty of Allied Health Sciences General Sir John Kotelawala Defence University Sri Lanka Email:nimantha.karunathilaka@kdu.ac.lk

http://orcid.org/0000-0002-5359-7168 DOI: http://doi.org/10.4038/cjms.v55i1.4911

\begin{abstract}
Background:

Recent studies have suggested that poor inhibitory control can lead to poor emotional aspect of eating behaviour resulting in obesity. Considering this, a study was conducted to assess the association between obesity, inhibitory control and emotional aspect of eating behaviour among young adults in Colombo District, Sri Lanka.
\end{abstract}

\section{Methods:}

Young adults of age $21-25$ years $(n=231)$ were studied. Body Mass Index (BMI) and Waist to Hip Ratio (WHR) were calculated to assess the generalized and central obesity, while inhibitory control was assessed through number of incorrect responses in Stroop, Stop signal and Go/nogo tasks. The emotional aspect of eating behaviour was assessed via selfadministered Three Factor Eating Questionnaire (Revised-18), which consists of three subscales; cognitive restraint, uncontrolled eating and emotional eating.

\section{Results:}

The mean age of the study sample was $23.4 \pm 1.4$ years with males comprising $51.9 \%$. There was a statistically significant group effect in mean incorrect responses of Stroop task and Stop signal task scores with normal, overweight and obese individuals $(\mathrm{p}<0.001)$. Further, obese individuals reported significantly higher scores in cognitive restraint and uncontrolled eating when compared to the normal counterparts in Three Factor Eating Questionnaire Revised-18 ( $\mathrm{p}<0.05)$. Among high WHR categories for males and females, there was a significantly higher incorrect response scores in Stroop task when compared to the normal WHR subjects $(\mathrm{p}<0.001)$. Three Factor Eating Questionnaire Revised-18 scores revealed that both males and females of high WHR category had a higher but insignificant cognitive restraint, uncontrolled eating and emotional eating when compared with normal WHR individuals $(\mathrm{p}>0.05)$. A positive significant correlation was observed in mean incorrect responses of Stroop task with cognitive restraint subscale $(\mathrm{r}=0.238, \mathrm{p}<0.001)$.

\section{Conclusion:}

Poor inhibitory control with abnormal emotional aspect of eating despite cognitive restraint was seen in those with obesity.

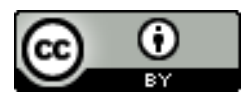

This is an open-access article distributed under the terms of theCreative Commons Attribution 4.0 International License, which permits unrestricted use, distribution and reproduction in any medium provided the original author and source are credited. 


\section{Background}

Statistics in World Health Organization (WHO) in 2005 showed that approximately 1.6 billion adults were overweight and 400 million adults were obese [1]. These figures have further increased to 1.9 billion overweight and 600 million obese by 2014 [1]. The prevalence of overweight, obese and central obesity among Sri Lankan adults were $25.2 \%, 9.2 \%$ and $26.2 \%$, respectively [2]. These figures are compatible with prevalence of obesity in regional countries [2]. Rapidly changing dietary practices and a sedentary lifestyle have led to increasing prevalence of adult obesity in the world [3]. The WHO has recommended Body Mass Index (BMI) as an accurate measurement for estimating total body fat while Waist to Hip Ratio [WHR] is used for assessing the pattern of distribution of fat; called central obesity [4].

Executive Functions (EF) is a term used to describe the higher order cognitive processes, coordinated by the prefrontal cortex of the brain. These functions are necessary for goal directed behaviours. Inhibitory control is one of the core processes that describes three broad categories of inhibition such as; inhibit pre-potent responses, inhibit ongoing responses and inhibit irrelevant information [5]. These functions emerge during early infancy, rapidly develop during childhood (512 years) and mature in late adolescence extending into the second decade of life [6]. It is anticipated that greater the inhibitory control, the higher the cognitive capability to overcome excessive eating desires [5].

Eating behaviour is a complex interplay of physiologic, emotional, social and genetic factors that influence meal timing, quantity of food intake, food preference, and food selection. Poor inhibition is an important parameter explaining eating behaviours [7-10]. It is associated not only with a higher BMI and obesity, but also with mediating variables, eating behaviours such as unhealthly food choices [7]. Recent studies have found a significant association between inhibition and eating behaviours particularly in the cognitive restraint domain amongst obese adults [8]. In addition, inhibitory control deficits are positively associated with unhealthy eating, including overeating (uncontrolled eating) in response to external food cues. It implies that these deficits motivate one to make food choices based on taste preferences without consideration of health value
[9]. Furthermore, higher levels of cognitive restraint and emotional eating are associated with higher BMI among adolescents [10]. Cognitive deficits in young adults with elevated BMI have been observed despite having no comorbid medical conditions that affect cognitive function [11-12].

Three-Factor Eating Questionnaire is a commonly used study instrument for assessing emotional aspect of eating behaviour. However, the original version of the Three-Factor Eating Questionnaire includes 51 items that limit its use in epidemiological studies [13]. Therefore, Karlsson and colleagues developed a reduced version of the original Three-Factor Eating Questionnaire consisting of 18 items, covering three main different domains corresponding to cognitive restraint, emotional eating, and uncontrolled eating in 2000 [14]. Cognitive restraint refers to conscious restriction of food intake in order to control body weight or to promote weight loss. Uncontrolled eating refers to tendency to eat more than usual due to a loss of control over food intake accompanied by subjective feelings of hunger. Emotional eating refers to inability to resist emotional cues thus increasing the tendency to eat. Further Lauzon and colleagues have proven that Three-Factor Eating Questionnaire (Revised-18) was appropriate to assess eating behaviour in the general population in both obese and non-obese persons [15].

Young adulthood is a crucial period in development of obesity. Self-doubt and intense psychological reorganization during this stage of life are some factors that may lead these young adults to take refuge in eating disorders [16]. Development of EF skills continues through late adolescence into early adulthood, coinciding with the growth and development of prefrontal cortex [17-18]. Therefore, late adolescence and young adulthood would be the best time to assess obesity related eating behaviour and inhibitory dysfunctions. There is a paucity of data on obesity related eating behaviour and executive function in a Sri Lankan setting. Further the emotional aspect of eating behaviour has wide cultural variations. Therefore, the aim of the study was to assess the association between the performances in inhibitory control and eating behaviour among normal, overweight and obese young adults in selected Medical Officer of Health $(\mathrm{MOH})$ divisions in Colombo District, Sri Lanka. 


\section{Methods}

A descriptive cross sectional community based study was conducted on 231 young adults (77 each of normal, overweight and obese), aged between 21-25 years, living in three periurban $\mathrm{MOH}$ divisions in the district of Colombo, Sri Lanka. The subjects were randomly selected using the electoral register of each Grama Niladari (GN) division by simple random sampling (using random number table). Each participant's BMI was assessed and allocated to the BMI category. Young adults who were pregnant, on special diet control and/or having endocrine/metabolic disorders that affect BMI were excluded. Informed written consent was obtained from the selected young adults. The Ethics review committee of the Faculty of Medical Sciences, University of Sri Jayewardenepura approved the study.

\section{Anthropometric Measurements}

Generalized obesity was determined using WHO Asian cutoff of BMI values; they were categorized as Normal (BMI between 18.5-22.9 $\mathrm{kg} / \mathrm{m}^{2}$ ), Overweight (BMI between 23.0-27.4 kg/m ${ }^{2}$ ), and Obese (BMI over $27.5 \mathrm{~kg} / \mathrm{m}^{2}$ ) [19]. Central obesity was measured using the WHO cutoff values of WHR for males and females; (Normal WHR for males was $<0.95$ and normal WHR for females was < 0.8) respectively [20]. A calibrated digital bathroom scale (WS-50-Mirofile, Switzerland) was used to measure weight while a calibrated Stadiometer (KT-GFO6A-Kindcare- China) was used to measure the heights of the participants.

\section{Three Factor Eating Questionnaire-R18}

Questionnaire was translated into Sinhala and Tamil and back translated to English to clarify any deviation of the translation process. The face validity and content validity was established with a group of experts. Subsequently the questionnaire was pre tested $(n=100)$ and culturally modified according to the standard guidelines in a similar population outside the study setting (Boralasgamuwa MOH area) [21]. The Questionnaire consists of 18 items on a 4-point response scale (definitely true/ mostly true/ mostly false/ definitely false). Responses to each of the 18 items are given a score between 1 and 4 and item scores are summed up into scale scores for each factor i.e. cognitive restraint, emotional eating, and uncontrolled eating. The raw scale scores are transformed to a $0-100$ scale [(raw score - lowest possible raw score)/possible raw score range*100] and the commonly used "half-scale" method is utilized to compensate for missing data on some items [14]. Cognitive restraint is better insight of dietary restraint (consciousness of restraining). Although it seems to go in the opposed direction, obese counterparts have awareness of their unhealthily dietary practices. However, uncontrolled and emotional eating may be affected through sensory organs/ inputs and stimulate the hunger center of the hypothalamus which may overcome the cognitive restraint. Further, poor inhibition has taken place due to uncontrolled eating. Therefore, higher values in each subscale indicate higher level of cognitive restraint, uncontrolled eating and emotional eating $[10,14]$.

\section{Inhibitory functions}

Pretested computerized inhibitory function tasks were used and they were administered in a quiet environment using a laptop with installed software. Tests were conducted, following a training session for each young adult. The duration of each test session was about 50 minutes with a 10 -minute rest half-way through the test. A separate quiet room was used for testing by the principal investigator, to minimize disturbances and to maintain a constant environment. Inhibition was assessed by Stroop task (ST), Stop signal task (SST) and Go/no-go task (GNG).

\subsection{Stroop task [ST]}

In this task, different colour words (such as green, red), written in the local languages (Sinhala \& Tamil), appeared on the computer screen one at a time. Sometimes the font colour of the printed word was the colour indicated by the word (congruent trials; e.g. the word 'red' printed in red font colour), but sometimes the colour word was printed in a different colour (incongruent trial; e.g. the word 'green' printed in blue font colour) [2224]. The participant's task was to say the colour that the word was printed in, disregarding the colour indicated by the printed word. There were 75 congruent and 25 incongruent trials in the test session. Incorrect answers included, apart from stating the wrong colour, errors that were corrected. The total number of incorrect answers on incongruent trials was used as a measure of inhibition, with higher scores representing poorer inhibition. 


\subsection{Stop-signal task [SST]}

The test was administered as a car game [22,25]. Every time a car appeared on the computer screen, participant had to press the space bar as fast as possible to drive away the car, while withholding a response when a STOP sign appeared at a certain delay after the car appeared. Each session consisted of 10 blocks of 24 trials, of which six were randomly placed stop-sign trials. The car was visible for $1500 \mathrm{~ms}$ and the inter-stimulus interval was $4500 \mathrm{~ms}$. A tracking mechanism was used, with the first stop-signal delay (the time between the appearance of the car and the STOP sign) set at $250 \mathrm{~ms}$. Each correct inhibition increased the delay by $50 \mathrm{~ms}$ (making it more difficult to inhibit at the next trial with stop sign), while failure to inhibit reduced the stop-signal delay by $50 \mathrm{~ms}$. The mean number of incorrect presses at stop trials (commission errors) were used as the inhibition score $[22,26]$.

\subsection{Go/no-go task [GNG]}

Pre-potent response inhibition was assessed when, the participant was presented with four different stimuli one at a time on the screen. The stimuli were two squares and two triangles in blue and red. In the first session, the participant was instructed to respond as quickly as possible by pressing a key each time a blue figure appeared on the screen (go-trials), regardless of shape. Subjects were instructed not to respond when a red figure appeared. In the second session, the participant was instructed to respond by pressing a button each time a square appeared, regardless of colour, and not to respond when a triangle appeared [22,27]. Together, the two consecutive sessions included 60 stimuli with $77 \%$ gotrials. The number of incorrect responses (commission errors) was used as a measure of inhibition.

\subsection{Data Analysis}

The data was entered into a data base and analyzed by SPSS statistical package (Version 23). ANOVA and independent sample student $t$ test were used to assess overall group differences on inhibitory function tasks and eating behaviours. Association between variables were assessed by Pearson correlation co-efficient. Significance level was kept as $\mathrm{p}<0.05$.

\section{Results}

The study sample was 231 young adults (77 each of normal, overweight and obese), aged between 21-25 years, living in three periurban $\mathrm{MOH}$ divisions in the district of Colombo, Sri Lanka.

\section{Demographic factors in obese, overweight vs. normal weight counterparts}

There was no significant difference in the distribution of gender, monthly income and education level between normal, overweight and obese categories in the study sample $\left(\chi^{2}=1.25, \mathrm{df}=2, \chi^{2}=0.35, \mathrm{df}=4, \chi^{2}=4.02, \mathrm{df}=4\right.$ respectively; $\mathrm{p}>0.05$ ) (Table 1$)$.

Table 1. Demographic characteristics of the study group $(\mathbf{n}=\mathbf{2 3 1})$

\begin{tabular}{lccl}
\hline & $\begin{array}{c}\text { Normal } \\
\mathbf{n = 7 7} \\
\text { Number(\%) }\end{array}$ & $\begin{array}{c}\text { Overweight } \\
\mathbf{n = 7 7} \\
\text { Number(\%) }\end{array}$ & $\begin{array}{c}\text { Obese } \\
\text { number(\%) }\end{array}$ \\
\hline $\begin{array}{l}\text { Gender } \\
\text { Male }\end{array}$ & $38(31.7 \%)$ & $38(31.7 \%)$ & $44(36.7 \%)$ \\
Female & $39(35.1 \%)$ & $39(35.1 \%)$ & $33(29.7 \%)$ \\
\hline $\begin{array}{l}\text { Monthly } \\
\text { Income }\end{array}$ & & & \\
Rs 0 - 20000 & $18(34.6 \%)$ & $16(30.8 \%)$ & $18(34.6 \%)$ \\
Rs 20000-30000 & $35(33.0 \%)$ & $35(33.0 \%)$ & $36(34.0 \%)$ \\
$>$ Rs 30000 & $24(32.9 \%)$ & $26(35.6 \%)$ & $23(31.5 \%)$ \\
\hline $\begin{array}{l}\text { Education } \\
\text { Level }\end{array}$ & & & \\
Up to GCE O/L & $9(53.0 \%)$ & $4(23.5 \%)$ & $4(23.5 \%)$ \\
Up to GCE A/L & $61(31.4 \%)$ & $65(35.1 \%)$ & $68(33.5 \%)$ \\
Up to Degree & $7(35.0 \%)$ & $5(25.0 \%)$ & $8(40.0 \%)$ \\
\hline & & & \\
& $($ Mean)(SD) & $($ Mean)(SD) & $($ Mean)(SD) \\
\hline $\begin{array}{l}\text { Age (Years) } \\
\left.\text { BMI (kg/m }{ }^{2}\right)\end{array}$ & $23.4(1.6)$ & $23.6(1.2)$ & $23.2(1.3)$ \\
WHR (Ratio) & $21.4(1.5)$ & $25.4(0.9)$ & $30.7(4.4)$ \\
$\bullet \quad$ Male & $0.94(.05)$ & $1.01(.06)$ & $1.06(.09)$ \\
• Female & $0.76(.08)$ & $0.83(.06)$ & $0.94(.08)$ \\
\hline
\end{tabular}

Comparison of Inhibitory tasks \& Three Factor Eating Questionnaire (R-18) subscales in normal, overweight versus obese individuals

A significant group effect was observed among BMI groups (normal, overweight and obese) and the performances in inhibitory tasks $(F[3,227]=31.7, \mathrm{p}<$ 0.001). Further, analysis of data by students $t$ test revealed that mean incorrect responses in Stroop task scores were significantly higher amongst obese $(\mathrm{t}[152]=-10.53, \mathrm{p}<0.001)$ and overweight subjects $(\mathrm{t}[152]=-4.06, \mathrm{p}<0.001)$ when compared with normal BMI subjects. Stop signal task scores were significantly higher amongst obese $(\mathrm{t}[152]=-4.63, \mathrm{p}<0.001)$ and overweight subjects $(\mathrm{t}[138]=-2.20 ; \mathrm{p}<0.05)$ when compared with normal BMI subjects. However mean incorrect responses in Go/no go task were not 
significantly different amongst the BMI groups $(\mathrm{p}>0.05)$ (Table 2). This indicates poor inhibitory control amongst the obese and overweight young adults when compared with normal counterparts.

Three-Factor Eating Questionnaire (Revised-18) scores (cognitive restraint, uncontrolled eating and emotional eating) among the three BMI groups (normal, overweight and obese) too showed a significant group effect ( $F[3$, $227]=8.94, p<0.001)$. Further analysis by Students $t$ test revealed that mean scores on cognitive restraint and uncontrolled eating were significantly higher in the obese group when compared with normal weight counterparts, (cognitive restraint: $\mathrm{t}[152]=-3.78 ; \mathrm{p}<0.001$; uncontrolled eating: $\mathrm{t}[152]=-2.44 ; \mathrm{p}<0.05)$, whilst no significant difference was noticed in cognitive restraint and uncontrolled eating among overweight and normal weight counterparts $(p>0.05)$. Further, the emotional eating score was not significantly different among the BMI groups ( $\mathrm{p}$ $>0.05$ ) (Table 2).

Table 2. Comparison of Inhibitory tasks scores and Three-Factor Eating Questionnaire (Revised-18) scores amongst normal, overweight and obese individuals

\begin{tabular}{|c|c|c|c|}
\hline & $\begin{array}{c}\text { Normal } \\
\mathrm{n}=77 \\
(\text { Mean })(S D)\end{array}$ & $\begin{array}{c}\text { Overweight } \\
\mathrm{n}=77 \\
(\text { Mean })(S D)\end{array}$ & $\begin{array}{c}\text { Obese } \\
\mathrm{n}=77 \\
\text { (Mean) (SD) }\end{array}$ \\
\hline \multicolumn{4}{|c|}{$\begin{array}{l}\text { Inhibitory task } \\
\text { scores }\end{array}$} \\
\hline $\begin{array}{l}\text { ST task } \\
\text { SST } \\
\text { GNG task }\end{array}$ & $\begin{aligned} 10.1 & (3.4) \\
2.0 & (1.5) \\
0.6 & (0.6)\end{aligned}$ & $\begin{aligned} 12.5 & (4.0)^{* *} \\
2.5 & (1.4)^{*} \\
0.5 & (0.5)\end{aligned}$ & $\begin{aligned} 15.3 & (2.5)^{* *} \\
3.0 & (1.3)^{* *} \\
0.7 & (0.7)\end{aligned}$ \\
\hline
\end{tabular}

\section{TFEQ- R18 scores}

$\begin{array}{lrrrrrl}\text { Cognitive Restraint } & 31.1 & (23.7) & 33.0 & (21.2) & 45.4 & (23.1)^{* *} \\ \text { Uncontrolled Eating } & 29.3 & (12.8) & 30.2 & (12.0) & 33.9 & (10.3)^{*} \\ \text { Emotional Eating } & 6.2 & (9.8) & 8.6 & (10.4) & 8.0 & (12.0)\end{array}$

$* * \mathrm{p}<0.001, * \mathrm{p}<0.05$

ST - Stroop task; SST - Stop signal task; GNG - Go/no go task

Comparison of Inhibitory tasks and Three-Factor Eating Questionnaire (Revised-18) subscales amongst WHR groups.

Significantly higher errors were observed in the mean incorrect responses of Stroop tasks and Stop Signal Tasks amongst high WHR category males $(\mathrm{t}[118]=-4.44$, $\mathrm{p}<0.001, \mathrm{t}[118]=-6.35, \mathrm{p}<0.001)$ compared with normal WHR males. The mean incorrect responses of Go/no-go tasks were not statistically significant in high WHR category males when compared to normal WHR males $(\mathrm{t}[118]=1.09, \mathrm{p}>0.05)$. Furthermore, a significantly higher score was found in the mean incorrect response scores of stroop tasks in females with high WHR $(\mathrm{t}[109]=-6.40, \mathrm{p}<0.001)$ when compared with normal WHR females. The mean incorrect responses of Stop Signal Tasks and Go/no-go tasks were not significantly different between high and normal WHR females $(\mathrm{t}[109]=-1.37, \mathrm{p}>0.05, \mathrm{t}[109]=0.30, \mathrm{p}>0.05)$ (Table 3$)$.

Further, Three-Factor Eating Questionnaire (Revised18) demonstrated that amongst both male and females WHR categories were not significantly different when comparing the mean scores of cognitive restraint, uncontrolled eating and emotional eating (Male; $\mathrm{t}[118]=-1.50, \quad \mathrm{p}>\quad 0.05, \quad \mathrm{t}[118]=-0.20, \quad \mathrm{p}>0.05$, $\mathrm{t}[118]=-1.02, \mathrm{p}>0.05$; Female; $\mathrm{t}[109]=-1.52, \mathrm{p}>0.05$, $\mathrm{t}[109]=0.12, \quad \mathrm{P}>\quad 0.05, \quad \mathrm{t}[109]=-0.77, \quad \mathrm{p}>0.05)$ respectively. However, higher mean percentages were observed in all the subscales of cognitive restraint, uncontrolled eating and emotional eating in bothmales and females with high WHR categories when compared to normal WHR counterparts except for emotional eating subscale for female (Table 3).

\section{Associations between Inhibitory tasks and Three- Factor Eating Questionnaire (Revised-18) subscales in the total sample.}

A positive significant correlation was observed in mean incorrect responses of Stroop tasks with cognitive restraint $(\mathrm{r}=0.238, \mathrm{p}<0.001)$ while no significant correlation was observed in (Stop signal tasks and Go/no-go tasks and with uncontrolled eating and emotional eating subscales of Three-Factor Eating Questionnaire (Revised-18).

\section{Comparison of Inhibitory tasks and Three-Factor Eating Questionnaire (Revised-18) subscales in gender}

The mean incorrect responses on Stroop tasks, Stop signal tasks and Go/no-go tasks were not significantly different amongst male and female subjects ( $p>005)$. The mean scores on cognitive restraint, uncontrolled eating and emotional eating of TFEQ R-18 were not significantly different between the male and female subjects $(\mathrm{p}>0.05)$. 
Table 3. Comparison of Inhibitory tasks and Three-Factor Eating Questionnaire (Revised-18) scores amongst WHR categories

\begin{tabular}{|c|c|c|c|c|c|}
\hline \multirow{2}{*}{ Inhibitory tasks } & $\mathbf{M} / \mathbf{F}$ & \multicolumn{2}{|c|}{$\begin{array}{c}\begin{array}{c}\text { Normal } \\
\text { WHR }\end{array} \\
(\mathrm{M}: \mathrm{n}=47 ; \\
\mathrm{F}: \mathrm{n}=47) \\
(\mathrm{M}) \quad(S D)\end{array}$} & \multicolumn{2}{|c|}{$\begin{array}{c}\text { High } \\
\text { WHR } \\
(\mathrm{M}: \mathrm{n}=73 \text {; } \\
\text { F: } \mathbf{n}=64) \\
(\mathrm{M})(S D)\end{array}$} \\
\hline & & & & & \\
\hline \multirow[t]{2}{*}{ ST task } & M & 11.7 & (3.7) & 14.0 & $(3.0)^{* *}$ \\
\hline & $\mathrm{F}$ & 9.8 & (2.9) & 14.5 & $(4.4) * *$ \\
\hline \multirow[t]{2}{*}{ SST } & M & 1.6 & (1.4) & 3.1 & $(1.2)^{* *}$ \\
\hline & $\mathrm{F}$ & 2.2 & (1.5) & 2.6 & $(1.3)$ \\
\hline \multirow[t]{2}{*}{ GNG task } & $\mathrm{M}$ & 0.6 & $(0.9)$ & 0.5 & $(0.6)$ \\
\hline & $\mathrm{F}$ & 0.7 & $(0.5)$ & 0.6 & $(0.4)$ \\
\hline \multicolumn{6}{|l|}{ TFEQ- R18 } \\
\hline \multirow[t]{2}{*}{ Cognitive Restraint } & $\mathrm{M}$ & 31.1 & (23.3) & 7.9 & $(24.4)$ \\
\hline & $\mathrm{F}$ & 34.2 & (23.5) & 0.8 & (22.1) \\
\hline \multirow[t]{2}{*}{ Uncontrolled Eating } & M & 30.6 & (11.3) & 31.0 & (12.3) \\
\hline & $\mathrm{F}$ & 31.3 & $(14.0)$ & 31.0 & $(9.5)$ \\
\hline \multirow[t]{2}{*}{ Emotional Eating } & $\mathrm{M}$ & 5.3 & (9.5) & 7.1 & $(9.5)$ \\
\hline & $\mathrm{F}$ & 8.5 & $(10.0)$ & 8.6 & (12.6) \\
\hline
\end{tabular}

**p $<0.001$ Mention ST, SST, GNG

\section{Discussion}

The present study was conducted to determine the association between the inhibitory control and eating behaviour amongst normal, overweight and obese young adults in a periurban area in Sri Lanka. The normal weight, overweight and obese groups were comparable on their educational status and socioeconomic status. However there was a negative association between inhibitory control and emotional aspect of eating behaviour amongst obese, overweight and normal weight young adults. Several studies have confirmed a positive association between inhibitory control and eating behaviour. The present study provides further support for decreased performance of inhibitory tasks amongst both generalized obese and centrally obese individuals. However, poor emotional aspect of eating behaviour was significantly associated only with generalized obesity. Furthermore inhibitory dysfunctions are significantly associated with cognitive restraint domain in Three-Factor Eating Questionnaire (Revised-18).

The cross sectional study conducted in various clinical setting by Fagundo and colleagues found that significant lower performances on inhibitory tasks (Stroop colour and word task) in middle age obese group when compared to healthy adults in
Spain [28]. However, a community based study conducted in the same year revealed the opposite effect with Stroop task in similar individuals [29]. Furthermore, another community based cross sectional study conducted by Gunstad et al. reveled that overweight and obese adults (age 20-50 years) exhibited poorer executive function test performance than normal weight adults which was similar to our findings [30]. Nevertheless, a longitudinal study conducted in USA revealed that higher BMI, waist circumference (WC) and WHR were associated with poorer performance on global cognitive function, memory and language while higher WHR was associated with decreased performance in executive function tasks when compared to normal WHR [31]. Another community based longitudinal study showed that WC and WHR were inversely related to multiple cognitive domains after adjustment for age, education and gender [32].

A Finish longitudinal study (2004-2009) amongst young adult found that higher BMI was associated with higher levels of cognitive restraint and emotional eating subscales while uncontrolled eating subscale wasn't significantly associated [10]. A cross sectional analytical study on adolescents and young women in Sweden revealed that dietary restraint was positively correlated with overweight and associated with lower energy 
intakes when compared to their normal weight counterparts. It also showed a significant negative association between energy intake and overweight [33]. A community based comparative study on French adolescents aged 11-16 years has shown that obese adolescents used greater cognitive restraint more than normal weight adolescents as a strategy for regulating their diet and maintaining their body image [34].

The results of the current study indicate that cognitive restraint, uncontrolled and emotional eating are higher, while the inhibitory control was poor among overweight and obese groups when compared with the normal weight group. The poor inhibitory control would have resulted in an inability to control the intake of food under emotional grounds in obese and overweight groups leading to higher BMI as found in other studies [35]. However, cognitive restraint is higher in the obese and overweight group when compared with the normal weight group suggesting that the higher ability to restrain diet has been developed after the participants reached a higher BMI. A similar pattern has been observed in another study [35].The results of the present study is also similar to a cross sectional study, where greater dyscontrol of eating behaviours in uncontrolled eating and emotional eating were related to lower inhibitory control in obese individuals when compared to lean individuals [36].

This study has several limitations. Poor inhibitory control is one of the many factors that determines the predisposition of the obese and overweight subjects to engage in overeating and uncontrolled eating. Eating behaviour may be determined by many cortical factors in addition to inhibition. These other factors were not taken into consideration in the present study. However the results of the present study can cautiously be interpreted that poor inhibitory control contributes a certain extent to the overweight and obesity observed amongst these young adults. Further, the study was not carried out in a very large population to be applicable to all ethnic groups and the gender distribution was small. The results warrant further longitudinal studies with an intervention component and would shed light on the contribution of inhibitory control in the development of obesity. The results however, provide primary data regarding the association of eating behaviour, BMI and inhibitory control amongst Sri Lankans. It has contributed to the

CJMS 2018; 55(1): 12-20 available data on the central control of eating behaviour in an Asian setting.

\section{Conclusion}

Results of the current study has further confirmed the association between deficits in inhibitory control and abnormal eating behaviour among obese and overweight young adults compared to normal weight subjects in this study population. The obese young adults in the study sample who have poor inhibitory control, had greater difficulty in maintaining controlled eating behaviour, thus resulting in excessive uncontrolled eating and excessive emotional eating. Future research should seek to further clarify the causality and the cause effect relationship between other executive functions and eating behaviour.

\section{Acknowledgments}

We acknowledge the research funding provided by the University of Sri Jayewardenepura (Grant Number. ASP/01/RE/MED/15/55). Authors are grateful to all participants and to Senior Professor Mirani Weerasuriya, Former Dean, Faculty of Allied Health Sciences, General Sir John KotelawalaDefence University for granting permission to conduct the study in the faculty premises.

\section{References}

1 WHO. Obesity and overweight, World Health Organization 2006.

http://www.who.int/mediacentre/factsheets/fs311/ en/print.htm (accessed: 02 February 2015).

2 Katulanda P, Jayawardena MAR, Sheriff MHR et al. Prevalence of overweight and obesity in Sri Lankan adults. Obes Rev 2010;11(11):751-56. doi:10.1111/j.1467-789X.2010.00746.x.

3 Gupta N, Goel K, Shah P et al. Childhood Obesity in Developing Countries Epidemiology, Determinants, and Prevention. Endocr Rev 2012;33:48-70. doi:10.1210/er.2010-0028.

4 WHO. Obesity: preventing and managing the global epidemic. Report of a WHO Consultation on Obesity. Geneva, Switzerland 2000.

http://www.who.int/nutrition/publications/obesity/ WHO_TRS_894/en/ (accessed: 2 February 2015).

5 Bunge SA, Dudukovic NM, Thomason ME et al. Immature Frontal Lobe Contributions to Cognitive Control in Children: Evidence from fMRI. Neuron. 2002;33(2):301-11. doi: 10.1016/S0896-6273(01)00583-9. 
6 Luna B, Garver KE, Urban TA, et al. Maturation of Cognitive Processes from Late Childhood to Adulthood. Child Dev 2004;75(5):1357-72. doi:10.1111/j.1467-8624.2004.00745.x

7 Bryant EJ, King NA, Blundell JE. Disinhibition: its effects on appetite and weight regulation. Obes Rev 2008;9(5):409-19. doi:10.1111/j.1467789X.2007.00426.x.

8 Price M, Lee M, Higgs S. Food-specific response inhibition, dietary restraint and snack intake in lean and overweight/obese adults: a moderatedmediation model. Int $J$ Obes (Lond)

2016;40(5):877-82. doi: 10.1038/ijo.2015.235.

9 Jasinska AJ, Yasuda M, Burant CF et al. Impulsivity and inhibitory control deficits are associated with unhealthy eating in young adults. Appetite 2012;59(3):738-47. doi: 10.1016/j.appet.2012.08.001.

10 Anglé S, Engblom J, Eriksson T, et al. Three factor eating questionnaire-R18 as a measure of cognitive restraint, uncontrolled eating and emotional eating in a sample of young Finnish females. Int J BehavNutrnd Phys Act 2009;6(41):1-7. doi: 10.1186/1479-5868-6-41.

11 Gunstad J, Paul RH, Cohen RA, et al. Relationship between body mass index and brain volume in healthy adults, Int $J$ Neurosci 2008;118(11):1582-93. doi: 10.1080/00207450701392282.

12 Gunstad J, Paul RH, Cohen RA, et al. Obesity is associated with memory deficits in young and middle-aged adults. Eating and Weight Disorders - Studies on Anorexia. Eat Weight Disord 2006;11(1):e15-19. doi: 10.1007/BF03327747.

13 Stunkard AJ \&Messick S. The three-factor eating questionnaire to measure dietary restraint, disinhibition and hunger. $J$ Psychosom Res 1985;29:71-83. doi:10.1016/0022-3999(85)90010-8.

14 Karlsson J, Persson LO, Sjostrom L et al. Psychometric properties and factor structure of the Three-Factor Eating Questionnaire (TFEQ) in obese men and women. Results from the Swedish Obese Subjects (SOS) study.Int J Obes Relat Metab Disord 2000;24:1715-25. doi: $10.1038 /$ sj.ijo.0801442.

15 de Lauzon B, Romon M, Deschamps V et al. The Three-Factor Eating Questionnaire-R18 Is Able to Distinguish among Different Eating Patterns in a General Population. J Nutr 2004;134(9):2372-80. doi: 10.1093/jn/134.9.2372.
16 Caflish M. \& Paris V. L'adolescentobe`se: uncasse-te^teou un de'fi? Me'decine et Hygie`ne 2000;58:2566-68. doi: 10.3305/nh.2015.31.6.8845.

17 Friedman NP, Miyake A, Young SE, et al. Individual differences in executive functions are almost entirely genetic in origin. $J$ ExpPsychol Gen 2008;137(2);201-25. doi: 10.1037/0096-3445.137.2.201.

18 Kuntsi J, Neale BM, Chen W, et al. The Image project: methodological issues for the molecular genetic analysis of ADHD. Behav Brain Funct 2006;2:27. doi: 10.1186/1744-9081-2-27.

19 WHO. Appropriate body-mass index for Asian populations and its implications for policy and intervention strategies. Lancet 2004; 363: 157-63. doi: 0.1186/1744-9081-2-27.

20 WHO. Waist Circumference and Waist-Hip Ratio. Geneva 2008. http://apps.who.int/iris/bitstream/10665/44583/1/9 789241501491_eng.pdf (accessed: 30 January 2016).

21 WHO. Process of translation and adaptation of the instrument 2017. http://www.who.int/substance_abuse/research_too ls/translation/en/(accessed: 15February 2017)

22 Hewage $\mathrm{C}$, Bohlin G, Wijewardena $\mathrm{K}$ et al. Executive functions and child problem behaviours are sensitive to family disruption: a study of children of mothers working overseas. Developmental Science 2011;14(1):18-25. doi:10.1111/j.1467-7687.2010.00953.x

23 MacLeod CM. Half a century of research on the Stroop effect: an integrative review. Psychological Bulletin 1991;109:163-203. doi: 10.1037/0033-2909.109.2.163.

24 Stroop JR. Studies of interference in serial verbal reactions. Journal of Experimental Psychology 1935;18:643-61. doi: 10.1037/h0054651.

25 Tillman CM, Thorell LB, Brocki KC, et al. Motor response inhibition and execution in the stop signal task: development and relation to ADHD behaviours. Child Neuropsychol 2008;14(1):42-59. doi: 10.1080/09297040701249020.

26 Logan GD, Schachar RJ, Tannock R. Impulsivity and inhibitory control. Psychological Science 1997;8(1):60-64. doi: 10.1111/j.1467-9280.1997.tb00545.x.

27 Berlin L, Bohlin G. Response inhibition, hyperactivity, and conduct problems among preschool children. Journal of Clinical Child and Adolescent Psychology 2002;31:242-51. doi: 10.1207/S15374424JCCP3102-09. 
28 Fagundo AB, de la Torre R, Jiménez-Murcia S et al. Executive functions profile inextreme eating/weight conditions: from anorexia nervosa to obesity. PLoS ONE 2012;7(8).

doi: 10.1371/journal.pone.0043382.

29 Ariza M, Garolera M, Jurado MA et al. Dopamine genes (DRD2/ANKK1-TaqA1 and DRD4-7R) and executive function: their interaction with obesity. PLOS ONE 2012;7(7). doi: 10.1371/journal.pone.0041482.

30 Gunstad J, Paul RH, Cohen RA et al. Elevated body mass index is associated with executive dysfunction in otherwise healthy adults. Compr Psychiatry 2007;48:57-61. doi: 10.1016/j.comppsych.2006.05.001.

31 Gunstad J, Lhotsky A, Wendell CR et al. Longitudinal Examination of Obesity and Cognitive Function: Results from the Baltimore Longitudinal Study of Aging. Neuroepidemiology 2010;34:222-29. doi: $10.1159 / 000297742$.

32 Dore GA, Elias MF, Robbins MA et al. Relation between central adiposity and cognitive function in the Maine-Syracuse study: attenuation by physical activity. Ann Behav Med 2008;35:34150. doi: 10.1007/s12160-008-9038-7.

33 Lluch A, Herbeth B, Mejean L et al. Dietary intakes, eating style and overweight in the Stanislas Family Study. Int J Obes Relat Metab Disord 2000;24:1493-99. doi: $10.1038 /$ sj.ijo.0801425.

34 Megalakaki O, Mouveaux M, Hubin-Gayte M, et al. Body image and cognitive restraint are risk factors for obesity in French adolescents. Eat Weight Disorders 2013;18:289-295. doi: 10.1007/s40519-013-0027-x.

35 De Lauzon-Guillain B, Basdevant A, Romon M et al. Is restrained eating a risk factor for weight gainin a general population? Am J Clin Nutr 2006;83:132-38. doi: 10.1093/ajcn/83.1.132.

36 Calvo D, Galioto R, Gunstad J, et al. Uncontrolled eating is associated with reduced executive functioning. Clin obes2014;4:172-79. doi: $10.1111 /$ cob.12058. 